\title{
TÉCNICA DE SUTA E IDENTIFICAÇÃO DE CÉLULAS NEOPLÁSICAS NO LIQUIDO CEFALORRAQUEANO
}

\author{
A. Spina-França * \\ A. DE B. B. MACHADO ** \\ J. R. PASQUalin ***
}

Atribui-se a Dufour em 1904 o primeiro relato da presença de células neoplásicas no líquido cefalorraqueano (LCR), após o que sucessivos estudos vieram demonstrar a utilidade do exame citológico do LCR para o diagnóstico da presença de processos tumorais no sistema nervoso central (SNC) e leptomeninges.

Em nosso meio, Lange foi o primeiro a estudar o assunto ${ }^{1}$; muitos dos estudos efetuados ulteriormente foram revistos por Mattosinho-França \& Spina-França ${ }^{2}$; posteriormente Scaff e col. reestudaram o problema, a propósito do registro de novo caso ${ }^{5}$. Muitos dos relatos referem-se a pleocitose do LCR por invasão leptomeníngea por processos neoplásicos (meningites ou meningopatias neoplásicas).

Em casos nos quais a citometria do LCR se apresenta normal ou ligeiramente alterada, o reconhecimento de células atípicas encontra, na parvicelularidade da amostra, elemento que dificulta a exata caracterização dos achados anormais. Este fato resulta em grande parte das dificuldades inerentes aos métodos empregados para enriquecimento da amostra a ser analisada pois, em sua maioria, tais métodos determinam modificações da estrutura e do interrelacionamento celular, comprometendo o exato reconhecimento das atipias.

Dentre os métodos preconizados para a obtenção de sedimentos de LCR ricos em células, o da centrifugação é o de emprêgo mais difundido embora seja aquêle que produz alterações citológicas das mais prejudiciais. Visando a contornar o problema Sayk, em 1954, introduziu a sedimentação gravitacional acelerada das células, método que melhora a perspectiva do exame, especialmente no que concerne ao reconhecimento de células neoplásicas. Desde então, reaberto o problema metodológico, numerosos autores ocuparamse da questão, várias tendo sido as técnicas de aprimoramento introduzidas nos últimos anos, conforme apontam Rich ${ }^{4}$ e Spriggs \& Boddington 7 .

Trabalho da Divisão de Neurologia do Hospital das Clínicas da Fac. Medicina da Univ. de São Paulo (Prof. H. M. Canelas), apresentado no IV Congresso Brasileiro de Neurologia, Pôrto Alegre, 1970): * docente; ** médico assistente; *** médico estagiário. 
Em publicação anterior ${ }^{6}$ foram salientadas as vantagens do emprêgo da variante da técnica de Sayk introduzida por Suta e difundida por Le Beau. Recentemente Mazalton e Daum ${ }^{3}$ publicaram revisão sôbre a utilidade do método. A técnica não representa um método ideal mas, pela sua simplicidade, baixo custo operacional e qualidade dos resultados obtidos, vern-se impondo como um dos métodos de preferência para o estudo da citologia do LCR.

O propósito dêste trabalho é mostrar os bons resultados que podem ser obtidos pela técnica de Suta no reconhecimento da presença de células neoplásicas no LCR, mediante a apresentação de 4 casos.

\section{A S U I S T I C A*}

Caso 1 - (HC-902.792) paciente de 8 anos de idade com diagnóstico clínico e hematológico de leucemia linfólde aguda que, três meses após o início dos sintomas, passou a apresentar quadro de neuropatia periférica e sinais de irritacão meningea. O LCR cisternal apresentava 201 células por $\mathrm{mm}^{3}$, algumas dispostas em agrupamentos. As células mostravam elevada relação núcleo-citoplasmática, cromatina em grumos e algumas estavam em divisão, permitindo caracterizá-las como linfoblastos (fig. 1).

Caso 2 - (L-36.684) paciente de 60 anos de idade com quadro de compressão medular. O LCR lombar apresentava 51 células e 108 hemácias por $\mathrm{mm}^{3}$. Dentre os elementos celulares foram encontrados agrupamentos de células atípicas de tamanho e morfologia variávels, consideradas como de tipo neoplásico (fig. 2). 0 paciente faleceu e o exame necroscópico demonstrou a presença de metástase de carcinoma brónquico no espaço sub-aracnóideo raqueano.

CASO 3 - (L-37.012) paciente de 28 anos de idade apresentou sindrome de cauda equina no pós-operatório tardio de melanoma maligno. O quadro agravou-se ràpidamente, vindo o paciente a falecer. O LCR lombar apresentava 7,3 células por $\mathrm{mm}^{3}$. Em sua maioria estas se apresentavam isoladas mas seus caracteres morfológicos permitiram orlentar o diagnóstico quanto à sua natureza neoplásica e ao seu caráter melanomatoso (fig. 3).

Caso 4 - (L-34.098) paciente de 12 anos de ldade que, cérca de dols anos depois de ter sido operado de tumor da fossa craniana posterior anatomo-patològicamente diagnosticado como meduloblastoma, apresenta sindrome de cauda equina. o LCR lombar apresentava 7 células por $\mathrm{mm}^{3}$, a maloria das quals congromeravase formando agrupamentos de número varíavel de células com caracteres inteiramente atípicos, permitindo afirmar sua natureza neoplásica (fig. 4).

\section{O M E N T A R I O}

Em condições normais as células presentes no LCR são reticulomonócitos e linfócitos, em proporções variáveis (citologia Classe I). Na presença de pleocitose, êsses mesmos elementos podem caracterizar o quadro citológico, bem

* Os autores agradecem aos Drs. L. C. Mattosinho-Franca e J. Guidugli Neto, Diretor e Assistente da Divisão de Anatomia Patológica do Hospital do Servidor Público do Estado de Sāo Paulo, pelas microfotografias. 

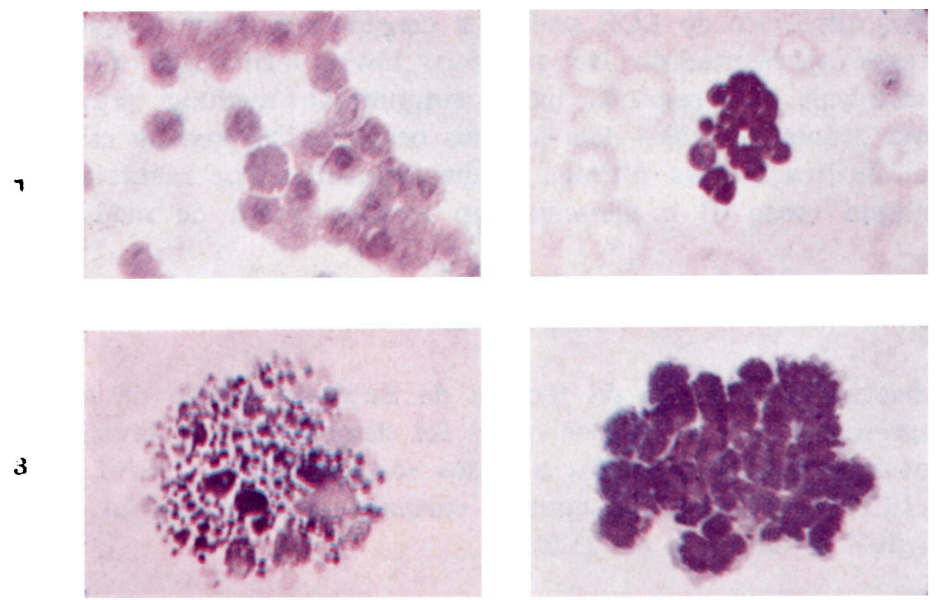

4

Fig. 1 - LCR cisternal. Caso 1. Menirıgopatia leucêmica (ieucemia linfóide aguda). Agrupamento de células com relação núcleo-citoplasmática elevada, cromatina em grumos e presença de mitoses (Classe V). Leishman; $400 \times$.

Fig. 2 - LCR lombar. Caso 2. Metástase intrarraqueana de carcinoma brônquico. Agrupamento de células de tamanho diverso com citoplasma escasso $e$ nucleos irregulares fortemente corados (Classe V). Leishman; $400 \times$.

Fig. 3- LCR lombar. Caso 3. Metástase intrarraqueana de melanoma maligno. Agrupamento com os dois tipos celulares que identificam a infiltração melanomatosa: célula tumoral (núcleo corado em vermelho) com pequenas arganelas melanino-secretoras (coradas em cinza) e células macrófagas carregadas de pigmento (Classe V). Leishman; $400 \times$.

Fig. 4 - LCR lombar. Caso 4. Meduloblastoma. Agrupamento compacto de células com relação núcleo-citoplasmática elevada, cromatina em grumos fortemente corados, citoplasma escasso e levemente basofilo (Classe V). Leishman; $400 \times$.

como polinucleares neutrófilos, células eosinófilas, monócitos, plasmócitos e, eventualmente, macrófagos e basófilos, podem ser encontrados conforme a natureza e o tipo da reação inflamatória responsável pela pleocitose (citologia Classe II).

A presença de células atípicas, seja com caracteres insuficientes para afirmar a suspeita de sua natureza neoplásica (citologia Classe III) ou com caracteres que permitem suspeitar de sua malignidade (citologia Classe IV) ou, ainda, com caracteres suficientes para afirmar sua natureza neoplásica (citologia Classe V), constitui gradação sucessiva para expressar a opinião do citologista quanto às características dessas células.

Essa clasificação é uma adaptação dos grupos de Papanicolaou e resulta de nossa experiência. 
O quadro citológico do LCR pode ser considerado como próprio à classe $\mathrm{V}$ nos 4 casos apresentados. No primeiro havia infiltração meníngea por células leucêmicas. No segundo havia compressão medular por metástase de carcinoma brônquico. Nos dois últimos ocorria sindrome de cauda equina por possível infiltração das últimas raízes raqueanas por metástase de melanoma maligno (caso 3) e disseminação leptomeningea de meduloblastoma (caso 4).

\section{$R$ E S U M O}

Para mostrar a utilidade da técnica de Suta no estudo da citologia do LCR são apresentados 4 casos nos quais foi demonstrada a presença de células de natureza neoplásicas. Os achados são analisados frente à citologia normal do LCR e classificados segundo variante da classificação de Papanicolaou aplicável à citologia do LCR.

\section{S U M M A R Y}

Suta's technique and identification of neoplastic cells in the cerebrospinal fluid.

Emphasizing the utility of the use of Suta's method for the study of CSF cytology, 4 cases are reported in which atypical cells of neoplastic origin were found. The findings are analysed in respect to the normal CSF cytology and classified in accordance with a variant of Papanicolaou's classification pertinent to CSF cytology.

\section{REFER E N C I S}

1. LANGE, O. - Cellulas neoplásicas no liquido cephalo-raqueano. Med. Cirurg. Farm. (Rio de Janeiro) 24:1, 1938.

2. MATTOSINHO-FRANÇA, L. C. \& SPINA-FRANÇA, A. - Método de Pananicolaou e pesquisa de células neoplásicas no líquido cefalorraqueano. Rev. paul. Med. (Sāo Paulo) 67:203, 1965.

3. MAZALTON, A. \& DAUM, S. - Cytologie du liquide céphalo-rachidien. NeuroChir. (Paris) 17 (suppl. 1):89, 1971.

4. RICH, R. - A survey of cerebrospinal fluid cytology. Bull. Los Angeles Neurol. Soc. $34: 115,1969$.

5. SCAFF, M.; RIVA, D. \& FERNANDES, W. S. O. - Carcinomatose meníngea. Arq. Neuro-Psiquiat. (São Paulo) 28:79, 1970.

6. SPINA-FRANÇA, A. - Câmaras de sedimentạcāo no estudo citológico do liquido cefalorraqueano. Arq. Neuro-Psiquiat. (São Paulo) 28:84, 1970.

7. SPRIGGS, A. I. \& BODDINGTON, M. M. - The Cytology of Effusions. Pleural, Pericardial, Peritoneal and of Cerebrospinal Fluid. Grune \& Stratton, New York, Ed. 2, 1968, pg. 43.

Clínica Neurológica - Caixa Postal 3461-01000, São Paulo, SP - Brasil. 